\title{
A Psicanálise de Freud e a Psicanálise de HoJe: as VICISSITUdES dO FEMININO NA ERA dOS EXTREMOS
}

\author{
Gabriel Pavani Brandino' \\ Thassia Souza Emidio \\ Barbara Sinibaldi ${ }^{3}$
}

\section{Resumo}

A presente pesquisa se propõe a fazer uma análise comparativa da questão do feminino no campo da psicanálise entre as formulações de Freud a respeito da feminilidade e as reflexões trazidas por psicanalistas inseridos no contexto atual da sociedade. Trata-se de uma pesquisa qualitativa pensando na questão do feminino nas teorizações freudianas e atuais e verificando dentro da bibliografia quais mudanças ocorreram na concepção da mulher dentro desta ciência, atrelando estas mudanças às transformações ocorridas na sociedade. Propõe-se realizar uma reflexão, não apenas o levantamento bibliográfico, mas também um exercício de pensamento trazendo um diálogo entre as obras de Freud, as teorizações atuais e a sociedade enquanto instrumento subjetivador para que as transformações no campo psicanalítico se concretizem.

PALAVRAS-CHAVE: Psicanálise. Feminino. Freud. Século XX. Sociedade.

\footnotetext{
1 Psicólogo. Bolsista EXPc-CNPq da Faculdade de Ciências e Letras de Assis, UNESP, Assis. Av. Dom Antônio, 2100, Parque Universitário, 19806-900, Assis, SP. (18) 3302-5800. gabrandino@gmail.com

${ }^{2}$ Professora Doutora em Psicologia do Departamento de Psicologia Clínica da Faculdade de Ciências e Letras de Assis, UNESP,Assis. Av. Dom Antônio, 2100, Parque Universitário, 19806-900, Assis, SP. (18) 3302-5884. thassia@assis.unesp.br

${ }^{3}$ Mestra em Psicologia pela Faculdade de Ciências e Letras de Assis, UNESP, Assis. Av. Dom Antônio, 2100, Parque Universitário, 19806-900, Assis, SP. (18) 3302-5800. sinibarbara@gmail.com
} 


\section{INTRODUÇÃO}

Deve-se ser cauteloso ao falar de feminino e masculino no campo da psicanálise, principalmente no que tange a obra de Freud. Em uma nota de rodapé, acrescentada em 1915 aos "Três ensaios sobre a teoria da sexualidade", Freud apresenta essa problemática afirmando que "os conceitos de 'masculino' e 'feminino', cujo conteúdo parece tão inambíguo à opinião corriqueira, figuram entre os mais confusos da ciência e se decompõem em pelo menos três sentidos" (FREUD, 1905, p. 207, grifos do autor). Freud afirma que ora "masculino" e "feminino" são empregados no sentido da atividade e da passividade, ora no sentido biológico, onde a diferença é localizada no campo anatômico, ora no sentido sociológico. Freud afirma ainda que a expressão destas características não se dá em sua pureza nos homens, mas o que ocorre é uma mescla de características dos sexos opostos na vida cotidiana dos sujeitos.

O sentido que interessa a Freud no tange à questão do feminino e do masculino é o sentido psicanalítico, cujos conceitos estão atrelados à atividade e passividade da libido, ou seja, ao caráter ativo da pulsão sexual que está ligado à característica masculina do desejo, enquanto que a posição passiva da libido está atrelada à expressão feminina do desejo. Freud afirma que a libido é essencialmente masculina, por que "a pulsão é sempre ativa”. (FREUD, 1905 [1996] p. 205).

Outro ponto que devemos nos deter antes de pensar o feminino em Freud é a perspectiva sócio-antropológica que este autor imprimiu em suas obras. Desde o momento em que Freud traz à luz sua teoria da sexualidade, ele carrega consigo uma questão que perpassará suas teorias durante todo seu percurso, o antagonismo entre a civilização e a vida pulsional do sujeito. Claramente este antagonismo trouxe diversas contribuições para o estudo da sexualidade humana e as pulsões libidinais, tendo em vista que Freud em seus "Três ensaios sobre a teoria da sexualidade" (1905), indica que haveria uma relação inversa entre a civilização e o livre desenvolvimento sexual, pois a civilização imporia renúncias ao sujeito. Logo, vemos aqui a necessidade de pensarmos não a mulher teorizada por Freud, mas sim como era essa mulher em seu contexto social, a qual Freud se dedicou em seus trabalhos, quais renúncias esta mulher do início do século $X X$ fez para que pudesse "civilizarse". 
Trata-se de uma pesquisa qualitativa pensando na questão do feminino nas teorizações freudianas e atuais e verificando dentro da bibliografia quais mudanças ocorreram na concepção da mulher dentro deste campo, atrelando estas mudanças às transformações ocorridas na sociedade.

Esta pesquisa se utiliza da psicanálise como referencial teórico, de cunho bibliográfico, propõe-se para análise de dados uma reflexão crítica da bibliografia levantada no desenvolvimento do projeto, cujo objetivo geral é refletir sobre as transformações no olhar da psicanálise para o feminino no século XX e XXI, com base a partir das mudanças do papel da mulher na sociedade.

\section{Freud, a Sexualidade e a Sociedade de Viena.}

Estudar o feminino não é uma tarefa simples. Freud afirma diversas vezes como o estudo do feminino é difícil e obscuro. Em seus primeiros trabalhos sobre a sexualidade, o impasse que o feminino coloca e que dificulta sua compreensão é apresentado no texto "Três Ensaios sobre a Sexualidade" (1905), onde afirma que "o desenvolvimento sexual [...] do homem é o mais consequente e o mais facilmente acessível a nossa compreensão, enquanto o da mulher representa até mesmo uma espécie de involução" (FREUD, 1905 [1996] p. 196). Esta incompreensão do feminino levou à suposição de que o desenvolvimento sexual das meninas se dava da mesma forma que nos meninos (FREUD, 1925), mas com o tempo a ideia de que possa haver um paralelismo no desenvolvimento sexual de ambos os sexos (FREUD, 1931) foi abandonada pelo próprio Freud.

É sabido que Freud morou em Viena durante grande parte de sua vida e foi lá que atendeu suas primeiras histéricas e formulou sua teoria do inconsciente, ou seja, quando Freud fala sobre o feminino ou quando pensamos sobre o que ele falou sobre o feminino devemos nos lembrar que ele falava de um feminino enclausurado na moral vienense, "em Viena, mais do que em qualquer outro lugar, elas [as mulheres] foram submetidas a uma clausura social que as manteve num isolamento que não possibilitava pensar em sua situação de opressão: tudo era natural para elas" (MOLINA, 2012, p. 50).

A vida social em Viena era extremamente regulatória e castradora, "a servidão em que vivem as vienenses cria um terreno particularmente favorável ao desenvolvimento das neuroses. Não é por acaso que os suicídios ocorrem em tão grande número na capital da Áustria-Hungria" (BERTIN, 1990, apud MOLINA, 2012), 
mas não apenas a vida social era castradora, a civilidade da mulher no começo deste século também envolvia grandes renúncias às pulsões libidinais, ou como Freud (1908) escreve "supressão dos chamados elementos pervertidos da excitação sexual" (p. 175, grifos do autor).

Freud, em sua teoria da sexualidade, problematiza a questão da sexualidade infantil e nos mostra ao longo de todo o seu trabalho que este ponto da sexualidade, tão primitivo e longínquo aos que procuram a análise, é parte fundamental da construção subjetiva. A renúncia ao destino das pulsões sexuais, ou seja, a renúncia ao objeto do desejo, durante o período de latência na criança faz parte do processo de civilizatório. Esta mudança no destino da pulsão é, na verdade, uma forma do aparelho psíquico negar a realização de um desejo ligado a um objeto específico, essa renúncia se caracteriza por um processo chamado sublimação, que nas palavras de Freud (1908) é "a capacidade de trocar seu objetivo sexual original por outro, não mais sexual, mas psiquicamente relacionado com o primeiro" (p. 174) este novo destino da pulsão relaciona-se com a cultura. Para Freud, a sublimação é um dos destinos da pulsão.

O movimento de sublimatório faz parte da constituição do sujeito e é de fundamental importância, mas não dá conta de todas as pulsões sexuais, "o sujeito consegue realmente, sob a influência da educação, e das exigências sociais, suprimir suas pulsões pervertidas, mas essa supressão é falsa, ou melhor, frustrada" (FREUD, 1908, [1996] p. 176), esta frustração provém de uma questão que Freud exemplifica da seguinte forma, "não é possível ampliar indefinidamente esse processo de deslocamento, da mesma forma que em nossas máquinas não é possível transformar todo o calor em energia mecânica" ( FREUD, 1908 [1996] p. 174).

Tento em vista a economia pulsional, o desejo do sujeito na impossibilidade de investir outro objeto, e mediante a ação do recalque que se afigura como outro destino da pulsão sexual responsável pelo pacto civilizatório, o aparelho psíquico diante vêse diante de duas opções: tentar realizar o desejo ou descarregar a pulsão pela via do sintoma, como afirma Freud (1908)

Se deixarmos de lado as modalidades mais leves de 'nervosismo' e nos atermos às doenças nervosas propriamente ditas, veremos que a influência prejudicial da civilização reduz-se principalmente à repressão nociva da vida sexual dos povos (ou classes) civilizados através da moral sexual 'civilizada' que os rege (p. 172). 
A repressão exercida pela sociedade pode ser percebida através do puritanismo presente na criação das meninas, exemplificado a partir do diário atribuído a Grete Lainer, um diário que mais tarde foi prefaciado por Freud, que no início do primeiro parágrafo já destaca a importância dessa obra: "isto é uma preciosidade. Nunca antes, creio eu, nada foi escrito que tenha nos permitido enxergar tão bem dentro da alma de uma jovem menina, pertencente a nosso estrato cultural e social, durante os anos da puberdade" (A YOUNG, 1952, p. 5, tradução nossa). Assim como vemos a ação da repressão social exemplificada nos escritos de Stefan Zweig, que afirma que "Para proteger as moças, [...] controlavam-se todos os livros que liam e, antes de mais nada, ocupava-se-as constantemente a fim de distraí-las dos pensamentos perigosos que poderiam Ihes ocorrer' (ZWEIG apud BERTIN, 1990, p. 115 - 116, grifo próprio).

A partir deste relato verídico da vida vienense de uma garota podemos perceber o quão tabu a questão da sexualidade era dentro daquele enquadramento social, assim como Freud (1929) afirma. De acordo com ele "os tabus, as leis e os costumes impõem novas restrições, que influenciam tanto homens quanto mulheres" (FREUD, 1929, p. 110). Desta forma, Freud faz uma análise do social, afirmando que é característico da civilização reprimir a sexualidade, principalmente infantil (momento mais importante do desenvolvimento sexual). A repressão repercute sobre as mais variadas formas de expressão sexual, até mesmo sobre a vida genital heterossexual, que também deve seguir uma lei.

\begin{abstract}
A civilização atual deixa claro que só permite os relacionamentos sexuais na base de um vínculo único e indissolúvel entre um só homem e uma só mulher, e que não é de seu agrado a sexualidade como fonte de prazer por si própria, só se achando preparada para tolerá-la porque, até o presente, para ela não existe substituto como meio de propagação da raça humana (FREUD, 1929, [1996] p. 111).
\end{abstract}

Retomando os conceitos psicanalíticos, Freud afirma que, assim como nos meninos, a primeira escolha objetal feminina é a mãe - que no caso das meninas é uma escolha pré-edipiniana, esta escolha que nos meninos se mantém, nas meninas sofre uma mudança e seu objeto agora se torna o pai.

Esta escolha objetal não é necessariamente anterior ao complexo de Édipo, Freud (1931) afirma que este tipo de escolha objetal já caracteriza uma entrada no complexo de Édipo, o que ocorre, segundo ele, nas meninas é a entrada no complexo de Édipo negativo, o qual pode tornar-se positivo ao passar do tempo. 

dos Extremos

O complexo de Édipo positivo é trazido por Freud (1923a) como o complexo de Édipo esperado, na qual a criança do sexo masculino, que tem a mãe como objeto de desejo sexual, o abandona e passa a ter maior identificação com o pai, surgindo assim o caráter da masculinidade na criança. O complexo de Édipo negativo e invertido seria portanto o que acontece com as meninas, pois, como foi trazido em Sexualidade Feminina (1931), a menina inicia a fase do complexo de Édipo com a mãe como objeto de desejo, após, este desejo é recatexizado para a figura paterna, a qual, enfim, manterá uma situação triangular.

De acordo com Freud (1931), a dissolução do complexo de Édipo ocorre quando a mulher "reconhece o fato de sua castração, e, com ele, também a superioridade do homem e sua própria inferioridade" (FREUD, 1931 [1996] p. 243), este fato reconhecido engendraria três caminhos às mulheres, a primeira sendo uma repulsão geral à sexualidade, a segundo a autoafirmação da masculinidade e por terceiro, sendo este o viés considerado normal, a tomada do pai como objeto de desejo para o encerramento completo do complexo e a dedicação à maternagem futura.

Entretanto, o abandono ao objeto original de seu desejo sexual não é o único no desenvolvimento sexual da menina. A chegada à puberdade torna-se também uma questão no formato da divisão das zonas erógenas, trazido por Freud como "qualquer [...] ponto da pele ou mucosa pode tomar ao seu encargo as funções de uma zona erógena, devendo, portanto, ter certa aptidão para isso. Assim, a qualidade do estímulo, mais do que a natureza da parte do corpo, é que tem a ver com a produção da sensação prazerosa" (FREUD, 1905 [1996] p. 173).

Assim, a ideia de substituição do clitóris pela vagina é de certa forma explicado, pois, uma vez o clitóris representando o não-pênis, ou seja, a não existência de um pênis, ou a existência de um pênis cortado, dá margem à supressão do estímulo sexual no clitóris, assim a mulher e seu papel de feminino "[encampam os fatores de] objeto e passividade. A vagina agora é valorizada como lugar de abrigo para o pênis; ingressa [a menina] na herança do útero" (FREUD, 1923b [1996] p. 163).

Quando a criança descobre que há uma diferença na anatomia da genitália é quando surge a problemática da castração, pois, uma vez que o menino vê os órgãos sexuais de uma menina ele percebe que há alguma coisa faltando, enquanto a menina, ao ver o pênis do menino se dá conta que lá há um pedaço de carne a mais. 
O complexo de castração é um fenômeno que ocorre em ambos os sexos porém, geram reações diferentes em cada gênero específico. Quando o menino se dá conta da falta do pênis na menina, este reage, assim como afirma Freud (1923b) que o menino rejeita o fato da menina não possuir o pênis e cria em seu imaginário a ideia de que ainda pode crescer. Os meninos "encobrem a contradição entre a observação e preconcepção dizendo-se que o pênis ainda é pequeno e ficará maior com o tempo" (FREUD, 1923b [1996] p. 161), paulatinamente, os meninos percebem que não crescerá o pênis, chegando a conclusão que "o pênis pelo menos estivera lá, antes, e fora retirado depois" (FREUD, 1923 [1996] p. 161).

A reação da castração nas meninas é imediata, "dessa ocasião em diante [as mulheres] caem vítimas da inveja do pênis" (FREUD, 1925, [1996] p. 285). A inveja do pênis caracteriza-se pela vontade, que perdura durante certo tempo, da mulher de obter um pênis para si. A falta anatômica pode causar um sentimento de inferioridade na mulher, gerando um desprezo por seu próprio gênero ao ver-se cortada.

Estes três pontos da sexualidade que foram discutidos nesta pesquisa representam como a sexualidade ao se falar no campo do feminino é vaga e sem muitas conclusões concretas no campo psicanalítico. As investigações freudianas não são suficientes para explorar todos os aspectos da vida feminina, mas pode-se notar aqui como a sociedade e a expressão da sexualidade caminham de mãos dadas, tanto na repressão de atos sexuais quanto em sua legitimação.

\section{Psicanálise e Sociedade Pós-Freud: Século XX e As Produções Atuais}

Avaliando o estudo feito anteriormente acerca da sociedade vienense do início do século XX, pode-se dizer que essa sociedade, assim como todo o mundo ocidental, sofreu uma metamorfose durante o passar do século $X X$, ou como nomeou Hobsbawm, a "Era dos Extremos". No período de escrita das teorias, poucas coisas transformaram a sociedade como no período pós-escrita, uma vez que Freud morreu em 1939, sua produção no foi atravessada pelo levante fascista europeu, o genocídio judeu, a queda das bombas atômicas, a separação da Europa e do mundo em ideologias econômicas, a revolução sexual e as guerras no extremo oriente, a queda do muro de Berlim e a queda do imperialismo na África, o fracasso comunista e o intenso processo de globalização.

Logo, quando pensamos na produção social-psicanalítica atual, já tratamos de um sujeito completamente diferente do sujeito que Freud um dia tratara, sendo assim, 
A Psicanálise de Freud e a Psicanálise de Hoje: As Vicissitudes do Feminino na Era dos Extremos

podemos concluir de forma lógica que o papel da mulher, assim como a forma que 0 mundo a olha, se transformou também. Desta forma, procuraremos demonstrar como diferentes momentos do século dos extremos afetaram diretamente as mulheres, como sua entrada no mundo do trabalho, o desenvolvimento de métodos contraceptivos, a revolução sexual e a conquista de direitos, transformou a forma de subjetivação da mulher e consequentemente a produção psicanalítica sobre elas.

Assim como o século $X X$ foi um século de diferentes acontecimentos, exigindo diferentes demandas, diferentes momentos de lutas das mulheres surgiram durante este período. As chamadas ondas do feminismo "ocorreram em épocas distintas, historicamente construídas conforme as necessidades políticas, o contexto material e social e as possibilidades pré-discursivas de cada tempo" (NARVAZ, KOLLER, 2006, p. 649).

A primeira fase ou onda do feminismo surge entre os anos de 1920 e 1930, levantando uma ideia de igualdade nos direitos civis, políticos e educativos, direitos estes que se reservavam principalmente aos homens. Durante este momento a psicanálise ainda está se fundando como teoria e surgem duras críticas à determinação psíquica que é apresentada por Freud no campo do feminino.

Uma das principais teóricas deste período é a francesa Simone de Beauvoir, que em seu principal livro, O Segundo Sexo, há um capítulo especialmente reservado para a revisão da psicanálise sobre as mulheres, cujos conceitos analisados seguem um mesmo movimento que esta pesquisa seguiu no capítulo anterior.

O primeiro momento do feminismo no século XX é acompanhado do pós I Guerra, da reestruturação do sistema de governo da Rússia e de outros países da Europa, devido à queda de monarquias e ao surgimento de novos Estados. Juntamente a este contexto político, o mundo cultural também sofre com grandes transformações, com o firmamento do modernismo, a implantação de ideias fascistas em produtos de mercado e a grave crise da bolsa de Nova York de 1929.

A segunda onda do feminismo ressurge nas décadas de 1960 e 1970, com maior força na França e nos Estados Unidos. Esta geração do feminismo toma cena após a sucessão de diversos acontecimentos importantes do século XX. Entre a primeira e a segunda onda do feminismo existe um salto histórico importante a ser relembrado. Esta geração do feminismo surge após a II Guerra Mundial, a separação do mundo por ideologias econômicas, pela criação - e dissolução - do Estado de Bem-Estar Social, a ascensão do neoliberalismo, a guerra do Vietnã, a guerra das 
Coreias, a primavera de 1968 e suas revoluções ideológicas, o movimento hippie, a criação da Organização das Nações Unidas, os julgamentos dos crimes de guerra, a corrida espacial, a instauração de ditaduras na América Latina, o apartheid e a luta do movimento negro na África do Sul e nos Estados Unidos, e o mundo experimenta, nesta época, o começo do que hoje chamamos de globalização.

O cenário mundial na época em que ressurge o feminismo não é o melhor momento do século, mas foi durante esta época que surgiram (e também morreram) diferentes líderes que abalaram a estrutura do mundo ocidental que estava posta. Martin Luther King Jr., Nelson Mandela, Winnie Mandela e outros lutaram frente ao movimento negro, batalhando pela igualdade de direitos entre negros e brancos.

Ainda neste período, no que interessa a esta pesquisa, o movimento feminista também fez muito barulho, com a queima do sutiã, o uso da minissaia e a luta pela liberdade sexual trouxeram novos paradigmas com os quais o mundo ocidentalcapitalista teve que lidar, juntamente com a invenção da pílula anticoncepcional, que tira a função de reprodução do sexo e coloca o prazer sexual em outro patamar, proporcionando uma nova vivência da sexualidade, uma vez que a maternagem pode ser evitada.

Como falado anteriormente, este período do feminismo toma maior força nos Estados Unidos e na França, compreensível através dos dados históricos levantados, uma vez que a maioria destes acontecimentos ocorreram ou iniciaram em terras estadunidenses ou francesas. A teoria estadunidense que surge durante este período tem como base "a denúncia da opressão masculina e a busca da igualdade", enquanto as francesas "postulavam a necessidade de serem valorizadas as diferenças entre homens e mulheres, dando visibilidade, principalmente, à especificidade da experiência feminina, geralmente negligenciada" (NARVAZ, KOLLER, 2006, p. 649).

Durante este período, a visibilidade da luta feminina se intensifica; a ONU declarou que 1975 seria o Ano Internacional da Mulher, o que "favoreceu a criação de uma fachada para um movimento social que ainda atuava nos bastidores da clandestinidade, abrindo espaço para a formação de grupos políticos de mulheres que passaram a existir abertamente" (SARTI, 2004, p. 39).

Durante a década de 1960, no cenário da psicologia, mais especificamente no campo da psicanálise, Lacan se torna um grande nome das teorias psicanalíticas, fazendo uma releitura das obras freudianas com um olhar estruturalista, ele ressurge 

dos Extremos

com questões sobre a teoria do inconsciente que abriu novas vertentes psicanalíticas, novas leituras e novos olhares.

Todavia, a problemática da subjugação da mulher ainda se fazia (e se faz) muito presente, apesar das conquistas do feminismo que vimos anteriormente, a mulher ainda ocupa um papel secundário. Vemos isso na teoria lacaniana, que segue o mesmo caminho de Freud e toma o fenômeno masculino e o adapta ao feminino. Podemos interpretar o fato de que não há nada que defina macho ou fêmea como um ponto interessante na discussão da determinação do sexo-gênero, todos são tomados como meninos. Uma vez que "la femme n'existe pas" ${ }^{4}$, somente o homem, e sua estrutura inconsciente existem e são passíveis de estudo, a mulher adaptar-se-ia às estruturas uma vez postas, por mais além do falo que ela esteja.

Podemos entender esta proposição lacaniana através de uma visão sociológica da construção social, pois nos deparamos com teorias que "tem como paradigma o desejo masculino em uma sociedade que se estrutura a partir de relações de dominação entre os gêneros, onde a mulher não é considerada como sujeito" (ARÁN, 2009, p. 662), o que na visão de Tort se torna "a versão formal do assujeitamento das mulheres ao fantasma de castração dos homens" (TORT apud ARÁN, 2009, p. 662).

É sob esta perspectiva do feminino que a psicanálise da metade do século $X X$ se norteia, entretanto, como veremos a partir de agora, outras teorias vêm discutir o gênero, agora através de novas perspectivas e de novos paradigmas.

Após essa década abaladora, estamos então há duas décadas para a virada do século e para a virada do milênio. O movimento feminista se vê, de repente, assim como todo o mundo, em outro momento social, dentro de outra conjuntura econômica e cada vez mais inserido dentro do que chamamos de processo de globalização.

Os anos de 1980 e 1990 compõem a época de surgimento da terceira onda do feminismo. Muitas coisas mudaram nestes vinte anos, pensando em escala mundial. A queda das ditaduras latino-americanas, a queda do muro de Berlim, a dissolução da União Soviética, a mundialização do capital, as guerras europeias dos anos 1990, o boom da tecnologia, o grande avanço da medicina, o aumento da circulação e veiculação de notícias, o vírus da AIDS, os movimentos de visibilidade LGBTTT e o surgimento da internet são fatores que transformaram a maneira como se vivia nas décadas anteriores.

\footnotetext{
4 "A mulher não existe" (LACAN, 1985).
}

174 Psicanálise \& Barroco em revista | v.16, n. 01 | julho de 2018 
Consequentemente as demandas de luta e as formas de luta mudam; neste período, principalmente na década de 1990, surgem os primeiros livros e debates acadêmicos sobre estudos de gênero, de sexualidade e o nascimento da teoria queer, abrindo espaço para a psicologia se inserir neste meio. A terceira onda traz em suas pautas uma "análise das diferenças, da alteridade, da diversidade e da produção discursiva da subjetividade" e se propõe a "enfatizar a questão da diferença, da subjetividade e da singularidade das experiências, concebendo que as subjetividades são construídas pelos discursos, em um campo que é sempre dialógico e intersubjetivo" (NAVAZ, KOLLER, 2006, p. 649).

Neste contexto da terceira onda que estamos inseridos, hoje não se fala mais de estudos sobre o feminino, mas tratamos agora de estudos de gênero, o gênero se tornou um marcador social da diferença, sua expressão e seus desdobramentos trazem à psicologia, à psicanálise e à sociedade uma visibilidade da minoria, através agora dos meios de comunicação expressa, que anteriormente não existia.

Os estudos de gênero e a teoria queer surgem acompanhando um movimento pós-estruturalista de Foucault e Derrida, debatendo as questões de universalidade oriundas das teorias lacanianas e das estruturalistas de Lévi-Strauss e partindo para uma discussão da singularidade do sujeito; questões acerca do controle sobre os corpos invade a área das ciências humanas, esbarrando na psicologia. Sob esta perspectiva pós-estruturalista, surgem duras críticas à psicanálise, assim como surgem algumas aproximações. Um dos novos caminhos que é apresentado à psicanálise é que esta "deve dialogar com movimentos sociais mais amplos, políticas culturais e questões relativas a gays, lésbicas, bi, trans, intersexo" (PORCHAT, 2013, p. 76).

Arraigada a esta ideia, nos passos da filosofia foucaultiana, uma problemática da binaridade se instala nas discussões filosóficas, psicológicas e psicanalíticas, principalmente quando estamos no campo do sexo/gênero/desejo. Ou seja, pensar toda identidade a partir de um conceito universalista (masculino) em contraposição com aquilo que não é masculino (do gênero feminino), como nos traz Butler, em Problemas de Gênero (2015) "a heterossexualização do desejo requer e institui a produção de oposições discriminadas e assimétricas entre 'feminino' e masculino'” ( $p$. 44). Butler ainda afirma, citando Wittig, que a redução da binaridade é um efeito da reprodução da heterossexualidade compulsória, que pode ser compreendido o fator que "tomaria meramente o lugar do falocentrismo como causa monolítica da opressão 
A Psicanálise de Freud e a Psicanálise de Hoje: As Vicissitudes do Feminino na Era dos Extremos

de gênero" (p. 45). Logo, podemos encarar a binaridade como o formato hegemônico do sexo/gênero/desejo, nesta óptica existiriam apenas dois formatos de expressão que devem se atrair pela lei da heteronormatividade compulsória.

A binaridade carrega consigo um problema que é discutido na teoria queer, apresentada acima, o posicionamento político dos corpos e de seus desejos e a livre expressão do gênero, ou seja, a binaridade excluí tudo aquilo que não faz parte da gama heteronormativa e marginaliza outras formas de desejo que não as hegemônicas.

Outra forma que a psicanálise passa a enxergar a sociedade e o sujeito neste contexto pós-estruturalista não universalista é a recusa de "uma concepção rígida do modelo edípico. O complexo de Édipo pode assumir várias formas culturais e pode, ainda, não ser considerado condição normativa da cultura" (PORCHAT, 2013, p. 79).

Desta forma, a psicanálise toma outra forma aos olhos dos novos teóricos que se atrevem a estudar as aproximações do pós-estruturalismo com a ciência do inconsciente, se comprometendo agora "com a tarefa de não permitir que os comportamentos sexuais, o que envolve corpos e identidades sexuais, sejam objetos de práticas de controle e normalização por parte da sociedade" (PORCHAT, 2013, p.80).

O gênero agora toma um caráter político, pois, ainda que ele seja um elemento que constrói as relações sociais a partir de diferenças anátomo-sexuais, ele ainda é "uma forma primeira de significar as relações de poder" (SOIHET, 1997, p. 103). Desta maneira, o gênero torna-se uma ferramenta para pensar as relações sociais e institucionais, principalmente quando pensamos nas relações de poder envolvidas. Podemos pensar o gênero, portanto, como um "meio de compreender as relações complexas entre diversas formas de interação humana" (SOIHET, 1997, p. 104).

O termo gênero foi introduzido na psicanálise por Robert Stoller, psicanalista americano, que estudava as questões transexuais. Ele se utiliza do gênero a fim de delinear os aspectos da psicossexualidade que são tomados como independentes do biológico (CECCARELLI, 2010). Não é apenas no campo da psicanálise que o gênero e a posição da mulher na sociedade incomodam, Boudieu, cientista social francês, mostra quase a razão pelo qual o gênero está sendo posto em discussão ultimamente, ele afirma que 
as diferenças visíveis entre o corpo feminino e corpo masculino que, sendo percebidas e construídas segundo os esquemas práticos da visão androcêntrica, tornam-se o penhor mais perfeitamente indiscutível de significações de valores que estão de acordo com esta visão: não é o falo (ou a falta de) que é o fundamento desta visão de mundo, e sim é essa visão de mundo que, estando organizada segundo a divisão em gêneros relacionais, masculino e feminino, pode instituir o falo [...] e instituir a diferença entre os corpos biológicos em fundamentos objetivos da diferença entre os sexos, no sentido de gênero construídos como duas essências sociais hierarquizadas (BOURDIEU, 2002, 43).

A questão de gênero na psicanálise, normalmente resulta do discurso falocêntrico e androcêntrico que se instalou nesta ciência - aqui devemos culpar a sociedade pela criação do estigma da mulher, não cabe culparmos Freud ou qualquer outro teórico pelo reflexo que a sociedade causou. Desta forma, vemos a psicanálise do gênero como uma luta, como uma saída para a apropriação dos novos saberes, novos comportamentos e novas formas de subjetivação que surgiram na Era do Extremos.

Afirmando que a mulher, socialmente, luta todos os dias para reconhecimento de seus direitos, Kon (2010) trata desta questão trazendo o diálogo psicanálise e sociedade, ao se remeter ao discurso falocêntrico conduzindo à ideia da incompletude da mulher,

o golpe do discurso falocêntrico recai prioritariamente sobre as mulheres. São elas aquelas especialmente subjugadas pela violência - por vezes silenciosa, mas não menos mortífera -, pela ideologia do falo que impera em nossa sociedade. [Nem] mesmo Freud, o grande libertador da fala da mulher no final do século XIX, não foi capaz de encontrar um destino que não o patológico inibição neurótica, masculinização e investimento libidinal no pai, na tentativa de reverter a castração (...) num discurso de consenso, à mulher falta o pênis. Impossível imaginar que o homem seria nomeado aquele a quem falta uma xoxota! Pois ao homem (o detentor do poder por sua própria natureza), é óbvio, nada falta! Não pode faltar! Alguém precisa ser completo! (KON, 2010, p. 19).

Aqui, podemos então pensar em uma nova forma de fazer psicanálise, "uma visão de como os homens e as mulheres são formados através do sistema de gênero, que discriminam uns e privilegiam outros" (LO BIANCO; ALMEIDA, 1997, p 134), ou seja, uma psicanálise que ultrapasse os preconceitos em relação ao gênero.

Nesta luta contra a misoginia, o machismo, o androcentrismo e o falocentrismo, pode-se ver a transformação do feminino na psicanálise, e podemos perceber uma constante luta pela dissolução da ideia falocêntrica psicanalítica, pois "acreditar-se portador de um poder de superioridade por ter o pênis como atributo do falo seria a crença maior da arrogância masculina em relação às mulheres" (BIRMAN, 1999, p. 11) e acreditar nesta superioridade dada pela psicanálise é acreditar numa falácia da 
A Psicanálise de Freud e a Psicanálise de Hoje: As Vicissitudes do Feminino na Era dos Extremos

hegemonia do homem; falácia, pois sem a mulher nunca despontar-se-ia a ciência do inconsciente.

Logo, podemos concluir que pensar o gênero em psicanálise não é apenas ter um novo olhar a respeito do desenvolvimento e da expressão psicossexual da mulher, mas também compreender, no sentido lato, as demandas que essas mulheres (sejam biologicamente mulheres, sejam socialmente mulheres) trazem à clínica tendo em vista o gênero feminino como um marcador social que promove e interrompe diferentes vontades e desejos, que limita a expressão do feminino, cuja clínica psicanalítica deve se debruçar para abarcar "as experiências e as angústias que sofrem as mulheres ou em que sentido o fato de ser mulher afeta esse processo terapêutico" (LO BIANCO; ALMEIDA, p. 133).

Pensar o gênero, agora, dentro da psicanálise, nos parece pensar no outro e "considerar a humanidade de qualquer ser" e dessa forma "lutar a favor de normas e convenções que permitem às pessoas respirar, desejar, amar e viver, e distingui-las das normas e convenções que restringem as próprias condições da vida" (PORCHAT, 2012).

Apesar de ainda percebermos que o machismo está presente através da "violência doméstica, sexual, familiar, a pouca presença das mulheres nos espaços públicos de poder institucional, a responsabilidade feminina pelo espaço privado, o machismo manifesto e o dissimulado, e o assédio sexual e moral no trabalho" (SCAVONE, 2008), o feminismo surge como uma luta que incomoda e que nos apresenta todas as relações de poder implicadas nos elos homem-mulher. A psicanálise envolvida com o feminismo tem essa responsabilidade, de entender na clínica o sofrimento dessas relações de poder e promover um empoderamento dos seres - especialmente os que se tornaram mulheres - frente à essas lutas.

\section{Considerações FinaIS}

Freud (1921) afirma que embora a psicanálise individual trate das demandas do inconsciente do sujeito, é praticamente impossível separar este sujeito de suas relações com outrem. Essa relação está invariavelmente relacionada à vida psíquica do indivíduo, o que dá espaço para que Freud afirme que "a psicanálise individual [...] é, ao mesmo tempo, também psicologia social" (FREUD, 1921, p. 77)

Logo tomamos essa premissa para podermos afirmar que o homem, enquanto ser social é invariavelmente atravessado por questões e marcações sociais. Ou seja,

178 Psicanálise \& Barroco em revista | v.16, n. 01 | julho de 2018 
a partir de um contexto social, econômico e político podemos traçar um perfil psicanalítico-social para entendermos melhor as demandas dos sujeitos.

A partir desta afirmação, podemos pensar as formulações que Freud trouxe sobre o feminino no começo do século XX e podemos pensar nas críticas feitas a ele no restante do século como um reflexo cultural. Foram apresentadas, no começo desta pesquisa, as vicissitudes envolvidas na sociedade vienense e as mudanças que ocorreram no mundo social a partir de então; assim podemos nos perguntar se o que Freud trouxe, ele enquanto pai da psicanálise é realmente machista em essência ou se, assim como qualquer outro sujeito, ele foi atravessado por questões e marcações culturais, o que se refletiu então sobre sua obra a respeito do feminino.

Tomamos, depois do exercício de pesquisa realizado, a conclusão de que a obra de Freud, no que tange o social, é um reflexo do momento vivido, assim podemos explicar o porquê da psicanálise do feminino ter se transformado e hoje não tratar apenas da mulher, mas de todas as formas de expressão de gênero, uma vez que a sociedade, hoje, não lida mais com a binaridade do sexo de forma tão corriqueira, hoje pode-se ver, ainda que pouco mas de maneira menos velada, diferentes formas de expressão dos gêneros e de suas sexualidades.

Visto desta forma, podemos voltar ao Freud e seu relacionamento teórico sobre o feminino. Como apresentado no primeiro capítulo, para ele a sexualidade da mulher ainda era confusa e de difícil compreensão. Entretanto, foram as mulheres de Freud que deram abertura e iluminaram a teoria do inconsciente que ele propôs.

Foi graças às histéricas do século XIX que Freud pode desenvolver uma teoria da psique humana que mudou o rumo da história. Freud foi o primeiro cientista que deu voz às mulheres e que as escutou, que deu voz à repressão e ao sofrimento psíquico. Não é a toa que vemos a evolução social ocorrer em tão pouco tempo, não é a toa que percebemos o empoderamento da mulher durante estes cem anos de recorte da pesquisa.

Pudemos confirmar nossa hipótese, que a sociedade implica veementemente no saber e no produzir psicanalítico, pois esta, enquanto ciência humana e social, não poderia estar a parte do contexto da realidade em sua teoria e em sua técnica. É dessa forma que podemos, então, construir uma psicanálise que abarque cada vez mais as necessidades da atualidade, que pense nesta nova formatação que vemos surgir agora neste novo milênio. 


\section{A Psicanálise de Freud e a Psicanálise de Hoje: As Vicissitudes do Feminino na Era dos Extremos}

\section{REFERÊNCIAS}

A YOUNG Girl's Diary. Londres: George Allen \& Unwin LTD, 1952.

ARÁN, M. A Psicanálise e o Dispositivo diferença sexual. Estudos Feministas, Florianópolis, V. 17, n. 3, 2009.

BERTIN, C. A mulher em Viena nos tempos de Freud. Campinas: Papirus, 1990.

BIRMAN, J. Cartografias do Feminino. São Paulo: Editora 34, 1999.

BOURDIEU, P. A dominação masculina. 2a Ed. Rio de Janeiro: Bertand Brasil, 2002.

BUTLER, J. Problemas de Gênero: Feminismo e Subversão da Identidade, $8^{a}$ edição, Rio de Janeiro: Civilização Brasileira, 2015.

CECCARELLI, P. R. Psicanálise, Sexo e Gênero: Algumas Reflexões. In: RIAL, C. PEDRO, J. ARENDE, S. (org.) Diversidade, dimensões de gênero e sexualidade. Florianópolis: Ed. Mulheres, 2010.

FREUD, S. (1905) Três Ensaios sobre a Sexualidade. Edição Standart Brasileira das Obras Psicológicas Completas de Sigmund Freud. Rio de Janeiro: Iamgo, 1996, v. VII.

. (1908) Moral Sexual 'Civilizada' e Doença Nervosa Moderna. Ibidem, v. IX.

. (1921) Psicologia de grupo e análise do Ego. Ibidem, v. XVIII.

. (1923a) O Ego e o Id. Ibidem, v. XIX

. (1923b) A Organização Genital Infantil (Uma Interpolação na Teoria da Sexualidade).

Ibidem, ibidem.

. (1925) Algumas Consequências Psíquicas da Distinção Anatômica Entre os Sexos. Ibidem, ibidem.

. (1929) O Mal-Estar na Civilização. Ibidem, v. XXI.

. (1931) Sexualidade Feminina. Ibidem, ibidem.

KON, N. M. "Ele não tem xoxota!": a lógica do falo ou a lógica da diferença? São Paulo: Revista Latino-americana de Psicopatologia Fundamental, v. 13, n. 3, p. 517-521, setembro 2010.

LACAN, J. O Seminário - XX: Mais, Ainda. Rio de Janeiro: Jorge Zahar Editor, 1985.

LO BIANCO, A. C. ALMEIDA, M. M. M. Articulações Psicanálise/Feminismo: Dificuldades de Novas Perspectivas. In: AGUIAR, N. (org.) Gênero e Ciências Humanas: desafio às ciências desde a perspectiva das mulheres. Rio de Janeiro: Record - Rosa dos Tempos, 1997.

MOLINA, J. A. O que Freud dizia sobre as mulheres. São Paulo: Cultura Acadêmica, 2011.

NAVAZ, M. G., KOLLER, S. H. Metodologias feministas e estudos de gênero: articulando pesquisa, clínica e política. Maringá: Psicologia e Estudo, v. 11, n. 3, p. 647- 654, 2006.

PORCHAT, P. Tópicos e desafios para uma psicanálise queer. In: TEIXEIRA FILHO, F. S. et. al. (org.) Queering: problematizações e insurgências na Psicologia Contemporânea. Cuiabá: EdUFMT, 2013, 232 p.

. Gênero, psicanálise e teoria queer. In: LEMOS DE SOUZA, L., et. al. (org.) Gênero, Corpo e @tivismos. Cuiabá: EdUFMT, 2012, 236 p.

SARTI, C. N. O feminismo brasileiro desde os anos 1970: revisitando uma trajetória. Florianópolis: Estudos Feministas, v. 12, n. 2, 2004. 
SCAVONE, L. Estudos de gênero: uma sociologia feminista? Florianópolis: Estudos Feministas, v. 16, n. 1, p. 173 - 186, 2008.

SOIHET, R. História, Mulheres, Gênero: Contribuições para um Debate. In: AGUIAR, N. (org.) Gênero e Ciências Humanas: desafio às ciências desde a perspectiva das mulheres. Rio de Janeiro: Record - Rosa dos Tempos, 1997. 


\title{
FREUD's PSYCHOANALYSIS AND TODAY'S PSYCHOANALYSIS: THE Vicissitudes OF the Feminine ALONG THE AGE OF EXTREMES
}

\begin{abstract}
This research proposes to do a comparative analysis of the feminine problem in the psychoanalysis field, between Freud's works about femininity and the reflections brought by psychoanalysts who are inside our current social context. It is a qualitative research, thinking over the feminine on Freudians' theories and current psychoanalysis theories; it is proposed to verify bibliographically which changes occurred in the concept of women inside this science; hitching those changes to the social transformations that occurred on the 20th century. It proposes to do a reflection, not only the bibliographic making, but also a thought exercise bringing a dialog between Freud's work, current psychoanalysis theories and the society as a subjectivity device for the transformations on the psychoanalytic field materialize itself.
\end{abstract}

KEYWORDS: Psychoanalysis. Feminine. Freud. 20th Century. Society. 


\section{La Psychanalyse de Freud et la Psychanalyse D'AUJOURD'HUI: LES VICISSITUDES DU FÉMININ DANS L’ÂGE DES EXTRÊMES}

\section{RÉSUMÉ}

Cette recherche se propose à faire une analyse comparative de la question du feminin au domaine de la psychanalyse entre les formulations de Freud sur la feminilité et les reflexions apporté pour psychanalystes qui ont s'intégrer dans le context actuel de la societé. Cette est une recherche qualitative, qui pense sur la question du feminin au theorizations freudienne et actuelle, et vérifier dans la bibliographie quelles changements ont arrive à le concept de femme dans cette science, en attrele cettes changement à les transformations qui ont arrivé dans la societé. II propose de faire une reflection, pas seulement un rélevé bibliographique, mais aussi une exercice de pensée, en amene un dialogue entre les oeuvres de Freud, les théories actuelles, et la societé comment une instrument de subjectivation pour que les transformations au domaine psychanalytique se concrétisent.

MOT-CLÉS: Psychanalyse. Féminin. Freud. 20e Sciècle. Société. 
A Psicanálise de Freud e a Psicanálise de Hoje: As Vicissitudes do Feminino na Era dos Extremos

Recebido em: 15-01-2018

Aprovado em: 26-03-2018

(C) 2018 Psicanálise \& Barroco em revista

http://www.seer.unirio.br/index.php/psicanalise-barroco/index

revista@psicanaliseebarroco.pro.br

Programa de Pós-Graduação em Memória Social — UNIRIO.

Memória, Subjetividade e Criação.

http://www.memoriasocial.pro.br/proposta-area.php

184 Psicanálise \& Barroco em revista | v.16, n. 01 | julho de 2018 